\title{
IDENTIFICATION OF COGNITIVE MANIPULATIONS THAT HAVE THE GREATEST IMPACT ON STUDENTS IN THE INTERNET
}

\begin{tabular}{l}
\hline \multicolumn{1}{c}{ Dr. Anna Zhdanko, Don } \\
\hline A R T I C L E I N F O \\
Original Research \\
Received: January, 08.2019. \\
Revised: March, 18.2019. \\
Accepted: April, 01.2019. \\
doi:10.5937/ijcrsee1901035Z \\
UDK \\
159.922.7.072-057.875 \\
81'23
\end{tabular}

Keywords:

cognitive manipulation,

critical thinking,

critical discourse analysis,

mass medium,

Internet,

social network.

\begin{abstract}
A B S T R A C T
The study puts an emphasis on exploring cognitive manipulations contained in the Internet resources (social networks and blogs) that have the greatest impact on students. The study was conducted with 159 students of Don State Technical University. 50 samples of media texts (of various formats) containing cognitive manipulation were taken from social networks sites and blogs. Focus group method, questionnaire, method of Critical Discourse Analysis and methods of mathematical statistics (Principal Component Analysis) were used for data collection and processing. The findings allow us to identify and describe the features of such cognitive manipulation as "presence effect", "focus on pros", "halo effect", "emotional resonance", "ambiguous language", "anonymous authority", "primacy effect", "exaggeration" and identify the manipulations that have the greatest impact on students. Recommendations aimed at reduction of the impact of manipulative techniques were suggested. The results of the present study may help teachers and psychologists in their work.
\end{abstract}

(C) 2019 IJCRSEE. All rights reserved.

\section{INTRODUCTION}

In our current digital age of information and communication technologies and mass media development, when printed text, is gradually being replaced by non-printed (Internet, video, television, electronic resources), of particular importance is the training of young people who will able to think critically and resist the negative influence from the outside. Nowadays, the Internet is a parallel school for young people. It's a source of education, entertainment, communication. Thanks to the Internet, young people have a developed virtual thinking (Asmolov, 2009). Along with

Corresponding Author

Dr. Anna Zhdanko, Don State Technical University, Rostov-on-Don, Russian Federation

E-mail: rostov-na-donu.an@yandex.ru

\section{(c) (i) $\odot$}

This work is licensed under a Creative Commons Attribution - NonCommercial - NoDerivs 4.0. The article is published with Open Access at www.ijcrsee.com the advantages, Internet has a number of significant drawbacks. The main disadvantage is expressed in the ability to have a manipulative impact on the human psyche. Young people, due to their unstable value-semantic and emotional spheres, are particularly exposed to this influence. Posts with extremist, suicidal, pornographic content are often posted in social networks, as well as posts promoting the use of narcotic, psychotropic substances, immoral lifestyle, etc. During an infection the cause of evil lies in the susceptibility of the living organism to the disease, when the body perceives foreign organism as its own. A similar situation occurs when one perceives someone else's message. Verbal manipulation of the subconscious mind, in particular hypnotic suggestion, is based on this peculiarity (Demyankov, 2017: 8).

In recent years, many authors have contributed to clearer understanding of the role of manipulation in mass media (press, radio, television, Internet) (Zelinsky, 2014; Voiskounsky, 2010; Demyankov, 2017; Livingstone, Mascheroni and Staksrud, 2018; Kara- 
Murza, 2004). But this problem continues to be relevant, as manipulators keep on inventing new techniques. Zelinsky S. A. defines manipulation as a conscious influence on the subconscious mind of other individuals with the goal of evoking certain neurotic dependency (Zelinsky, 2014). Inherent biologically programme of our behaviour is insufficient for us to become people. It is supplemented by a program recorded in the signs of culture. So, our behaviour is always under the influence of other people, and we can not protect ourselves from this impact by some rigid barrier (KaraMurza, 2004).

Since our research is related to the study of cognitive manipulation, we would like to focus our attention on its peculiarities. $\mathrm{T}$. Van Dijk defines cognitive manipulation as a form of mind control involving interference in the processes of understanding, formation of mental models and representations (Van Dijk, 2006: 359). Chumakova V. V., Daineko V. V. define cognitive manipulation as a psychological influence on the learner, which contributes to the actualization of his specific knowledge and meanings, the formation of a certain way of thinking that affects human behaviour. Cognitive manipulation is based on the selection variants of information symbols with the purpose of changing the internal cognitive algorithms of students' thinking and their cognitive activity (Chumakova and Daineko, 2015). We define cognitive manipulation as a verbal and non-verbal influence on the recipient's psyche, which contributes to the actualization of the latter's certain meanings and knowledge and affects his way of thinking and behaviour. To the verbal component of cognitive manipulation, scientists refer such manipulative methods of influence as the mismatch of titles to the content, the use of elevated vocabulary for marking "ours" and low, negative-estimated vocabulary for marking "strangers", incoherent answers, etc. (Mikhaleva, 2009; Sukhanov, 2018; Wodak, 2006). To the non-verbal cognitive manipulation we refer use of colour, photos, intonation, gestures, etc. (Van Dijk, 2006; Voiskounsky, 2010; Burgoon, Blair and Strom, 2008).

Despite the fact that theoretical and experimental investigations devoted to the impact of cognitive manipulations in mass media have already been carried out (Demyankov, 2017; Dzyaloshinsky, 2005; Livingstone, Mascheroni and Staksrud, 2018; Maillat and Oswald, 2011; Van Dijk, 2006; Zelinsky, 2014 , etc.) the problem of impact of cognitive manipulations contained in Internet re- sources (social nets, blogs) has been considered extremely little in Russian science. In our opinion, the main task of modern teachers is to study virtual thinking of students by means of the study of virtual reality peculiarities. In order to study virtual reality teachers have to get acquainted with modern information technologies. We support the idea of L. Stosic that the majority of teachers have psychological aversion of technical innovations (Stošić and Stošić, 2013). Definitely it doesn't contribute to the understanding of students' nature.

There are a lot of cognitive manipulations used in Internet discourse, but we would like to study 8 types widely used manipulation according to S. G. Kara-Murza and S. A. Zelinsky, namely: emotional resonance, ambiguous language, primacy effect, presence effect, exaggeration, focus on pros, anonymous authority and halo effect (Kara-Murza, 2004; Zelinsky, 2014).

"Emotional resonance" is a type of manipulation where a certain mood with the simultaneous transmission of propaganda information is created. Emotional resonance allows removing the psychological protection that a person builds at the mental level, consciously trying to protect himself from propaganda or "brainwashing". Being protected from propaganda messages, at the rational level, a person is always able to build a system of counterargument and reduces all efforts to impact to zero. If the impact on a person occurs on an emotional level, outside of his conscious control, no rational counterarguments in this case work. The media is always trying to evoke strong emotions in a wide audience (Zelinsky, 2014).

"Ambiguous language" technique is expressed in the incoherence of the message, the use of complex terminology, etc.

The key principle of "primacy effect" is "who tells the world the first word is always right". Psychologists have found that the first candidate who convincingly presents himself as a winner during the election campaign have advantages. To such conclusions came $\mathrm{K}$. Hovland and other scientists from Yale University who believed that we tend to give preference to the information that came first. It is very difficult to change an already formed opinion, (Hovland 1954).

The "presence effect" manipulation was firstly put into practice by Nazi propaganda. Today it is described in all textbooks on journalism, psychology, sociology. It includes a number of tricks that simulate reality. They are constantly used in "reports from the 
battlefields" and in the "criminal" chronicle, fabricating shooting, catching bandits, car accident, etc. Everything looks as if the operator is in terrible excitement.

"Exaggeration" is used with the aim to over-emphasize something, make it better or worse than it really is.

The aim of "focus on pros" manipulation is to highlight only pluses of an event or person. Thus, the manipulator manages to push his idea.

"Anonymous authority" manipulation is based on references made to non-existent authority with the purpose to give weight to the information in the eyes of ordinary people.

"Halo effect" manipulation is based on two common stereotypes-misconceptions.

- being close to a famous or high-ranking person somewhat increases the status in the eyes of others.

- a successful person is considered being successful in all spheres.

Thus, the main aim of the research is to identify cognitive manipulations contained in the Internet resources (social networks and blogs) that have the greatest impact on students.

The research objectives are:

- to reveal cognitive manipulations in Internet resources (social networks, blogs);

- to identify the manipulations that have the greatest impact on students ;

- to describe cognitive mechanisms of manipulations used in Internet resources.

\section{MATERIALS AND METHODS}

The research was conducted on a sample selected from students of Don State Technical University ( $\mathrm{N}=159)$. 50 samples of texts (of various formats) containing cognitive manipulation were taken from social networks sites and blogs. It was carried out in 2018. Participants were undergraduate students. Among them, most were first year students (84 or $52 \%$ ), second year students ( 25 or $15,7 \%$ ), third year students (50 or $31 \%)$. The research was based on the descriptive, qualitative and quantitative methods of analysis. Focus group method, questionnaire and method of critical discourse analysis were used for data collection and processing. To reach statistically valid conclusions, the IBM SPSS Statistics 23.0 software package was used.

Our study started with the selection of texts containing cognitive manipulation. The method of critical discourse analysis allowed us to identify the type of manipulation. With the help of critical discourse analysis method we managed to reveal 8 types of cognitive manipulation. Method of critical discourse analysis is widely used by psycholinguists. N. Fairclough was the first to introduce this method (Fairclough, 1995). After determining the type of manipulation, we calculated the frequency of their use in texts.

Then 50 texts containing cognitive manipulation were offered to 159 students to determine the manipulations that have the greatest impact on students. This was not done simultaneously, as the study was conducted using the focus group method. The focus group method is widely used in psychology, sociology and pedagogy. There were about 12-13 students in each focus group. Thus, the focus group discussion was held in 13 focus groups. The task for the students was to get acquainted with the texts containing cognitive manipulation and express their belief or disbelief about the information contained in them on a five-point scale with the argumentation of their point of view. Students also expressed their attitude by selecting one out of five statements offered in Attitude Scale Questionnaire (I strongly believe-1, I believe - 2, I neither believe nor disbelieve -3 , I do not believe -4 , I do not believe at all - 5).

For data processing was also used Principal Component Analysis.

\section{RESULTS}

The study of the Internet resources (https://twitter.com/navalny; https://www. youtube.com/channel/UCgxTPTFbIbCWfTR9I2-5SeQ; https://navalny.com/; https:// www.instagram.com/navalny/; https://twitter. com/klichqotes) allows us to analyze 50 media texts, reveal cognitive manipulations and describe their cognitive mechanisms.

Method of Critical Discourse Analysis was used to determine the type of cognitive manipulation and frequency of its use in texts. The results are shown in Table 1. More than one manipulation was used in one and the same text. 
Table 1. Eight main types of cognitive manipulation used in Internet resources (social networks, blogs).

\begin{tabular}{|c|c|c|c|c|c|c|c|c|}
\hline № & 1 & 2 & 3 & 4 & 5 & 6 & 7 & 8 \\
\hline $\begin{array}{c}\text { frequency } \\
\%\end{array}$ & 80 & 70 & 65 & 60 & 60 & 50 & 40 & 40 \\
\hline $\begin{array}{l}\text { Here, } \\
2-" \mathrm{a} \\
3-" \mathrm{f} \\
4-" \mathrm{p} \\
5-" \mathrm{~h} \\
6-" \mathrm{p} \\
7-" \mathrm{p} \\
8-" \mathrm{a}\end{array}$ & $\begin{array}{l}\text { nor } \\
\text { ocu } \\
\text { ores } \\
\text { ialo } \\
\text { rim } \\
\text { xag } \\
\text { imb }\end{array}$ & $\begin{array}{l}\text { ymo } \\
\text { s on } \\
\text { ence } \\
\text { effec } \\
\text { acy } \\
\text { gera } \\
\text { guol }\end{array}$ & $\begin{array}{l}\text { emo } \\
\text { us a } \\
\text { pros } \\
\text { effec } \\
\text { t" } \\
\text { fffec } \\
\text { ion' } \\
\text { is la }\end{array}$ & $\begin{array}{l}\text { iona } \\
\text { thor } \\
\text { t" } \\
\text { t" } \\
\text { ngua }\end{array}$ & $\begin{array}{l}\text { ll res } \\
\text { rity" }\end{array}$ & & & \\
\hline
\end{tabular}

"Emotional resonance" is used in $80 \%$. This manipulation is marked by emotional and evaluative comments. For expressing disapproval negative-estimated vocabulary is used ("We endured poverty, humiliation!" "How long can we endure?" "It's absurd...", "it's shocking", "corrupt", "fascists", etc.). For expressing approval elevated vocabulary is used Non-verbal component of manipulation is expressed by intonation, loud voice, shocking pictures.

"Ambiguous language" technique is used in $40 \%$. It is expressed in the incoherence of the speech, the use of complex terminology, neologisms, jargons, redundant information, complementary polysemy, etc. For example: "If the ball bursts, it will not be inflated. Rather it will be inflated, but another one" (https:// twitter.com/klichqotes). Here we can find redundant information and incoherence of the speech.

"The primacy effect" is used in $50 \%$. Students were offered several media texts on one and the same subject. They tend to memorize better and believe more the information mentioned in the first text.

"The presence effect" manipulation (used in 60\%). Verbal component of manipulation is expressed by exact indication of the place and time of the action, detailed commenting of the events. The author conveys own feelings and emotional state and expresses his own attitude to what is happening, mainly with the help of the pronoun "I". The narration is in the present tense. Non-verbal component of manipulation is expressed by sounds, images, visuals which help to cause a particular reaction and feelings.

"Exaggeration" is used in $40 \%$. Verbal component of manipulation includes the use of plural instead of singular, exaggeration of real numbers, interjections, exclamation, presenting material as sensational. Non-verbal component of manipulation is expressed by intonation, loud voice, impulsive gestures and mimics. Falsifying facts is widely used in exaggeration. For example, a group of people of 50-100 people is shown and it is said that thousands of people have come to support this or that activity.

"Focus on pros" manipulation (used in $65 \%$ ) is marked by highlighting only pluses of an event or a person and hiding minuses.

"Anonymous authority" manipulation is used in $70 \%$. Verbal component of manipulation is marked by the use of such expressions as "scientists have established...", "doctors recommend...", "a source from the nearest presidential entourage, who wished to remain unknown, reports...", etc.

"Halo effect" manipulation (used in $60 \%$ ) Verbal component of manipulation is marked by the use of the names of famous people with the reference to their words. Nonverbal component of manipulation is marked by the use of the images of famous people. And famous people are often depicted as "saviors".

Focus group method, questionnaire and Principal Component Analysis were used to identify the manipulations that have the greatest impact on students (Table 2).

Table 2. Total Variation Explained "Identifying effective manipulation"

\begin{tabular}{|c|c|c|c|}
\hline \multirow{2}{*}{$\begin{array}{l}\text { Manip- } \\
\text { ulation }\end{array}$} & \multicolumn{3}{|c|}{ Initial Eigenvalues } \\
\hline & Total & $\%$ of Variance & Cumulative \% \\
\hline 1 & 2,082 & 26,022 & 26,022 \\
\hline 2 & 1,479 & 18,493 & 44,515 \\
\hline 3 & 1,271 & 15,884 & 60,399 \\
\hline 4 & 1,052 & 13,148 & 73,547 \\
\hline 5 & 0,829 & 10,368 & 83,915 \\
\hline 6 & 0,564 & 7,049 & 90,965 \\
\hline 7 & 0,432 & 5,405 & 96,370 \\
\hline 8 & 0,290 & 3,630 & 100,000 \\
\hline
\end{tabular}

Here, manipulations (types of manipulation are sorted by the degree of importance):

1 - "halo effect";

2 - "ambiguous language";

3 - "anonymous authority";

4 - "emotional resonance";

5 - "primacy effect";

6 - "presence effect";

7 - "focus on pros";

8 - "exaggeration"' 
Table 2 shows that four eigenfactors have values greater than 1.0. Therefore, only four factors are selected for analysis. The first factor explains $26,022 \%$ of the total variance, the second factor explains $18,493 \%$, the third factor explains $15,884 \%$ and the fourth factor explains $13,148 \%$.

Table 3. Rotated Component Matrix "Selection of groups of components"

\begin{tabular}{|c|c|c|c|c|}
\hline & \multicolumn{4}{|c|}{ Component } \\
\hline & 1 & 2 & 3 & 4 \\
\hline halo effect & 0,871 & & & \\
\hline ambiguous language & $-0,782$ & & & \\
\hline anonymous authority & 0,680 & & & \\
\hline emotional resonance & & 0,880 & & \\
\hline primacy effect & & & 813 & \\
\hline presence effect & & $0,467 \quad 0$ & 677 & \\
\hline focus on pros & & & & 782 \\
\hline exaggeration & & & & 0,766 \\
\hline
\end{tabular}

The rotated matrix of components allows interpreting the results of the analysis.

The presented factor loads should be understood as correlation coefficients between variables and factors. So "halo effect" variable is strongly correlated with factor 1, namely, the correlation value is 0,871 . "Ambiguous language" variable is strongly correlated with factor $1(-0,782)$. "Anonymous authority" variable is also correlated with factor $1(-0,680)$. "Emotional resonance" variable is strongly correlated with factor $2(0,88)$. "Primacy effect" $(-0,813)$ and "presence effect" $(0,677)$ variables are correlated with factor 3. "Focus on pros" $(0,782)$ and "exaggeration" $(-0,766)$ variables are strongly correlated with factor 4 . In most cases, the inclusion of a separate variable in a single factor carried out on the basis of the correlation coefficients is single-valued. In exceptional cases, for example, as in the case of the presence effect variable, the variable can refer to two factors at the same time.

Options of influencing factors on respondents can be attributed in the following order to four factors.

Factor 1:

- "halo effect";

- "ambiguous language";

- "anonymous authority".

Factor 2:

- "emotional resonance";

- "presence effect".

Factor 3:

- "primacy effect";

- "presence effect'.
Factor 4:

- "focus on pros";

- "exaggeration".

Factor 1 includes manipulations based on the stereotype that famous people, leaders are perceived as successful and intelligent in almost all spheres. This in turn increases the credibility of their words and actions. "Ambiguous language" also belongs to this factor. It happens due to the fact that such a disadvantage as the imperfect speech of many famous people is compensated by some advantages of these people.

Factor 2 includes manipulations based on overcoming protective barriers to obtaining unwanted information. "Emotional resonance" manipulation is aimed at the formation of certain emotions. "Presence effect" manipulation also affects the unconscious of the individual, causing heat feelings and emotions. As a result the censorship of the psyche is weakened.

Factor 3 includes primacy effect manipulation and presence effect manipulation. The essence of primacy effect manipulation is based on the specifics of our psyche to take on faith the first received information. The emotional component of "primacy effect" manipulation enhances the effect of "presence effect" manipulation.

Factor 4 includes manipulations based on the inability of the individual's psyche to react properly and instantly on a big amount of distorted information.

The Scree plot of cognitive manipulation (Figure 1) shows that after the first four components the eigenvalues are less than 1.0. This again supports a four-component solution.

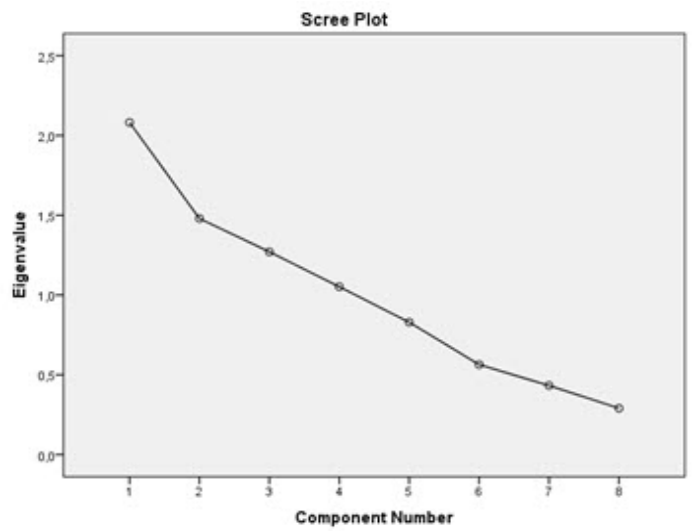

Figure 1. Scree Plot of cognitive manipulation 


\section{DISCUSSIONS}

The research aimed to examine cognitive manipulation in Internet resources (social networks, blogs) and identify the manipulations that have the greatest impact on students.

According to the results presented in Table 2 "halo effect" manipulation has the greatest impact on students. It is based on psychological property to attribute talents in all spheres to the person talented in one area. But there a lot of examples when people who do perfectly one thing are helpless at doing other things. It means that the majority of students have stereotypes and poor forecasting ability.

The second manipulative technique influencing greatly on students is "ambiguous language". Usually recipient hesitates to ask again the meaning of a term or doesn't have such an opportunity and it gives the manipulator the opportunity to turn the situation in the right direction, allows him to be in an initially advantageous position and achieve the necessary result.

The third effective manipulation is "anonymous authority" manipulation. References to non-existing authority give the information certain reliability.

The fourth effective manipulation is "emotional resonance". It means that the majority of the students trust their emotions without critical analysis. The technology of this manipulation is based on such a property of the individual's psyche as emotional infectability. It is known that in the course of life a person builds certain protective barriers from obtaining undesirable information. But this becomes possible when protective mechanisms are removed. It's possible to overcome the barrier of the mind causing an explosion of emotions in the individual.

The fifth place belongs to "primacy" manipulation. The essence of this manipulation is based on the property of our psyche to take on faith the first received information. Even the fact that later we can get more reliable information, often does not exclude the fact of subconscious distrust of it. So, later it is quite difficult to change the formed opinion (Zelinsky, 2014).

The "presence effect" manipulation is on the sixth place among the most influential. Such a great influence is explained by the influence on the unconsciousness. The information supplied in advance by manipulators is offered to the audience by pseudo eyewitnesses who pass it so sincerely. This falsified information often reaches the effect on the audience, because it affects the unconsciousness of the individual. As a result the censorship of the psyche is weakened and it accepts the information without determining its false essence.

In "focus on pros" manipulation the idea of manipulators is promoted by focusing only on the pros. In this case students don't take into consideration the fact that each phenomenon has its pros and cons. Critical analysis of information is required.

"Exaggeration" manipulation is based on the presentation of the material as sensational. As a result the individual's psyche does not have time to react properly, an unnecessary excitement is created, and it reduces the criticality. Therefore the manipulators reach the expected result. The received information falls into the unconscious of the individual. Then it affects the consciousness, distorting the meaning.

The effectiveness of manipulation is determined by many factors: age, gender, life experience, leading representative system, emotional state, health, etc. In our opinion the effectiveness of manipulation is determined by the spiritual maturity of people, their willingness to be deceived (Zhdanko, 2018).

Young people are often not successful in relating actions with their motives and con-sequences. Their emotional and cognitive spheres are not stable. It also increases the manipulative effect.

The unawareness of the essence of manipulation also increases the risk of being manipulated. So it's important to be aware of the laws of manipulation in order to fight against manipulation.

The degree of manipulation impact also depends on a person's leading representative system. Academician V. M. Kandyba (Kandyba, 2004) notes that depending on the dominance of the activity of the left or right hemisphere of the brain, a person subconsciously or unconsciously thinks and realizes everything that happens in the external or internal reality according to one of three main internal psychophysiological (representative) systems:

1 . Reality is perceived mostly through words. Verbal and logical thinking dominates.

2 . Reality is perceived mostly through visual images. Eidetic thinking dominates.

3 . Reality is perceived through the senses and kinesthetic feelings.

The success of manipulation is guaranteed when the manipulated believe that everything that happens is natural. So, manipulation 
exits in a false reality where its presence is not felt. This false reality is created by the media, in particular by Internet. Very often others opinions are perceived by people as their own conclusions. The main condition for successful manipulation is the lack of critical processing of information.

Thus, an important step in the fight against manipulation is the formation of critical thinking. Critical thinking is "a mental activity that result in an ability of a person to process information, namely, to interpret, analyze, evaluate, formulate conclusions, prove, and be self-reflexive about his own mental activities» (Facione, 2013: 5). A developed critical thinking allows encoding and decoding information. We support D. Kloosters' idea who distinguishes five main features of critical thinking: thinking;

- critical thinking is an independent

- critical thinking starts with the problem statement;

- critical thinking is characterized by convincing arguments;

- critical thinking is a social thinking;

- critical thinking is a self-reflexive thinking (Klooster, 2001).

Often our prejudices prevent us from thinking critically. Critically thinking person is not someone who has no prejudices, everyone has them, but someone who is aware of his prejudices.

Age features of psychological and pedagogical development of students contribute to the development of critical thinking, namely, the reflection of own life path, self-realization, self-expression, the ability to hypothetical-deductive reasoning, that is, the ability to highlight and study the individual properties of a complex subject, push and test hypotheses about their qualities, properties, and relationships. At this age, students develop patterns of behavior and value orientations.

Dealing with various kinds of messages teachers and students should remember about following rules that will help to form critical thinking:

- messages create "reality" in a certain way and with a certain purpose;

- each of us interprets messages in his own way: perception and interpretation of messages depend on such factors as gender, age, education, culture, education, life experience, etc.;

- messages have a certain ideology and value system;

- messages have their own way of en- coding information.

\section{CONCLUSIONS} tempt:

The author of the study made an at-

- to reveal cognitive manipulations (emotional resonance, anonymous authority, focus on pros, presence effect, halo effect, primacy effect, exaggeration, ambiguous language) and the frequency of their use in Internet resources (social networks, blogs);

- to describe cognitive mechanisms of manipulations;

- to identify the manipulations that have the greatest impact on students.

In the light of the results obtained from the study, recommendations for teachers aimed at reduction of the impact of manipulative techniques were suggested:

- teach students that each message (printed, visual, audio) is created with a certain purpose;

- teach students that each message has a certain ideology and value system;

- teach students to decode information using different types of analyses (semiotic, narrative, etc.);

- teach students that the interpretation of messages depends on such factors as gender, age, education, culture, education, life experience, etc.

Manipulation might be dangerous not only for a young persons' life but also for the future of the whole state. Teachers and family can help greatly in solving this problem.

This research contributes to the expanding of empirical knowledge in pedagogy, psychology, sociology.

\section{ACKNOWLEDGEMENTS}

The author gratefully appreciates all research participants and anonymous reviewers from the journal.

\section{Conflict of interests}

The author declares no conflict of interest.

\section{REFERENCES}

Asmolov, A. G. (2009). From we-media to I-media: Identity transformations in the virtual world. Psychology in Russia: State of the art, 2(1). https://www.ingentaconnect.com/content/doaj/ 20746857/2009/00000001/00000002/art00007 
Burgoon, J. K., Blair, J. P., \& Strom, R. E. (2008). Cognitive biases and nonverbal cue availability in detecting deception. Human Communication Research, 34(4), 572-599. https://doi. org/10.1111/j.1468-2958.2008.00333.x

Chumakova, V. V., \& Daineko V. V. (2015). Cifrovye obrazovatel'nye resursy i kognitivnye manipulyacii v obuchenii [Digital educational resources and cognitive manipulation in training]. Izvestiya VGPU. Pedagogicheskie nauki [News of VSPU. Pedagogical science]. 2(267), 41-44. http://izvestia.vspu.ac.ru/izvestia_2015_v267 $\mathrm{N} 2 . h \mathrm{html}$

Demyankov, V. Z. (2017). Transfer znanij i kognitivnaya manipulyaciya [Knowledge transfer and cognitive manipulation]. Voprosy kognitivnoj lingvistiki [Issues of Cognitiv Lingvistics], 4, 5-13. https://doi.org/10.20916/1812-3228-20

Dzyaloshinsky I. M. (2005). Manipulyativ nye tekhnologii v mass-media [Manipulative techniques in mass media]. Vestnik Moskovskogo universiteta. Zhurnalistika [Bulletin of Moscow University. Journalism], 10, 56-76. https://elibrary. $\mathrm{ru} /$ item.asp? $\mathrm{id}=11750051$

Facione P. A. (2013). Critical Thinking: What it is and Why it Counts. Measured Reasons and the California Academic Press, Millbrae.

Fairclough, N. (1995). Critical Discourse Analysis. Boston: Addison Wesley.

Hovland, C. I. (1954). The Effects of the Mass Media of Communication In Handbook of Social Psychology 2(2), 1062-1103 by Carl I. Hovland edited by Gardner Lindzey http://www.citeulike. org/group/14507/article/9360718

Kandyba, V. M. (2004). Technique of hypnosis in reality. The technique of a hidden human control. Saint-Petersburg: Lan'.

Kara-Murza S. G. (2004). Manipulation of consciousness. Moscow: Algorithm. (In Russian).

Klooster, D. (2001). What is critical thinking. Thinking Classroom, 4, 36-40.

Livingstone, S., Mascheroni, G., \& Staksrud, E. (2018). European research on children's internet use: Assessing the past and anticipating the future. New Media \& Society, 20(3), 1103-1122. https:// doi.org/10.1177/1461444816685930

Livingstone, S., \& Third, A. (2017). Children and young people's rights in the digital age: An emerging agenda. New Media \& Society, 19(5), 657-670. https://doi.org/10.1177/1461444816686318

Maillat, D. \& Oswald, S. (2011). "Constraining context: a pragmatic account of cognitive manipulation". In Hart, Christopher (ed.).Critical discourse studies in context and cognition. Amsterdam: John Benjamins, 65-80. https://doi.org/10.1075/ dapsac. 43

Mikhaleva, O. L. (2009). Political discourse. The specificity of manipulative influence. Moscow: "LIBROKOM". (In Russian).

Novković-Cvetković, B., \& Stanojević D. (2018). Integrating digital technologies into teaching process. Teme, 42(4), 1219-1233. https://doi. org/10.22190/TEME1804219N

Sperber, D., Cara, F., \& Girotto, V. (1995). Relevance theory explains the selection task. Cognition, 57(1), 31-95. https://doi.org/10.1016/00100277(95)00666-M

Stanković, Z., Maksimović, J., \& Osmanović, J. (2018). Cognitive theories and paradigmatic research posts in the function of multimedia teaching and learning. International Journal of Cognitive Research in Science, Engineering and Education/IJCRSEE, 6(2), 107-114. https://doi. org/10.5937/ijcrsee1802107S

Stanojevic, D. M., Cenić, D., \& Cenić, S. (2018). Application of computers in modernization of teaching science. International Journal of Cognitive Research in Science, Engineering and Education:(IJCRSEE), 6(2), 89-106.https://doi. org/10.5937/ijcrsee1802089S

Stošić, L., \& Stosic, I. (2013). Diffusion of innovation in modern school. International Journal of Cognitive Research in Science, Engineering and Education:(IJCRSEE), 1(1), 5-13. http://www. ijcrsee.com/index.php/ijcrsee/article/view/7

Sukhanov, Y. Y. (2018). Political discourse as object of linguistic analysis. RUDN Journal of Language Studies, Semiotics and Semantics, 9(1), 200-212. http://dx.doi.org/10.22363/2313-22992018-9-1-200-212

Van Dijk, T. A. (2006). Discourse and manipulation. Discourse \& Society, 17(3), 359-383. https://doi. org/10.1177/0957926506060250

Voiskounsky, A. E. (2010). Internet addiction in the context of positive psychology. Psychology in Russia: state of the art, 3, 541-549. https://doi. org/10.11621/pir.2010.0026

Wodak, R. (2006). Mediation between discourse and society: assessing cognitive approaches in CDA. Discourse Studies, 8(1), 179-190. https://doi. org/10.1177/1461445606059566

Zelinsky S.A. (2014). Manipulation of the masses and psychoanalysis. CANADA.: Altaspera Publishing \& Literary Agency Inc. 396. http://lit.lib. $\mathrm{ru} / \mathrm{z} /$ zelinskij_s a/text 0430-1.shtml

Zhdanko, A. P. (2018). Identifying extremist behaviour in youtube comments and the formation of antyextremist values. Paper presented at the $5^{\text {th }}$ International Multidisciplinary Scientific Conference on Social Sciences and Arts SGEM 2018. Vienna, Austria. https://doi.org/10.5593/sgemsocial2018H/11

\section{Internet sources:}

https://twitter.com/navalny

https://www.youtube.com/channel/UCgxTPTFbIbCWfTR9I2-5SeQ

https://navalny.com/

https://www.instagram.com/navalny/

https://twitter.com/klichqotes 